\title{
Trajetória Tecnológica e Sustentabilidade Ambiental na Cadeia de Produção da Carcinicultura no Brasil ${ }^{1}$
}

\author{
Elda Fontinele Tahim², Marlene Nunes Damaceno ${ }^{3} \mathrm{e}$ \\ Inácio Fernandes de Araújo ${ }^{4}$
}

Resumo: Este artigo analisa a trajetória tecnológica do cultivo de camarão no Nordeste brasileiro e suas implicações ou limitações para a adoção de inovações sustentáveis ambientalmente. Desse modo, uma abrangente pesquisa empírica foi realizada, usando dados secundários e entrevistas semiestruturadas com vários agentes envolvidos no cultivo do camarão. Assim, foi possível identificar o perfil desse setor de atividade com base em sua trajetória de desenvolvimento desde o início de sua produção no Brasil. Os principais resultados do estudo apontam que a trajetória tecnológica dessa indústria revelou limitações, mas, também, algumas oportunidades para a geração de inovações sustentáveis, especialmente no estágio atual.

Palavras-chaves: trajetória tecnológica, regime tecnológico, inovação ambiental, sistema de inovação, cultivo de camarão.

\begin{abstract}
This paper analyzes the technological route of shrimp farming in Northeast Brazil and their implications or limitations for the adoption of environmentally sustainable innovations. Thus, an extensive empirical research was performed, using secondary data and semi-structured interviews with various agents involved in shrimp farming industry. Therefore, it was possible to identify the profile of this activity based on its development trajectory since the beginning of its production in Brazil. The main results of this study indicate that the technological path of this industry revealed limitations, but also some opportunities for the generation of sustainable innovation, especially at the current stage.
\end{abstract}

Key-words: technological trajectory, technological regime, environmental innovation, innovation system, shrimp farming.

Classificação JEL: Q10, Q20, O33.

DOI: http://dx.doi.org/10.1590/1234-56781806-94790570106

1. Data de submissão: 4 de fevereiro de 2016. Data de aceite: 22 de abril de 2018.

2. Universidade Estadual do Ceará (Uece), Fortaleza-CE, Brasil. E-mail: fontineletahim@gmail.com

3. Instituto Federal do Ceará - Campus Limoeiro do Norte (IFCE), Limoeiro do Norte-Ceará, Brasil. E-mail: marlene@ifce.edu.br

4. Universidade Federal de Juiz de Fora, Juiz de Fora-MG, Brasil. E-mail: inaciofaj@gmail.com 


\section{Introdução}

O cultivo de camarão marinho, embora tenha uma história recente em relação aos demais segmentos da aquicultura, constitui o principal vetor de desenvolvimento de tecnologias e serviços para o setor aquícola mundial, favorecendo seu crescimento de forma acelerada em diversos países (NATORI et al., 2011; ROCHA, 2013). No Brasil, a indústria do cultivo de camarão foi objeto de grandes transformações no período de 1978, início de sua produção comercial, até 1996, com a introdução de um pacote tecnológico para o cultivo do camarão do Pacífico (Litopenaeus vannamei) e, posteriormente, com os avanços científico e tecnológico nos anos 2000 - nesse período essa atividade atingiu o auge em termo de produtividade (NATORI et al., 2011; ROCHA, 2006a). Esse avanço decorreu, em grande parte, da criação de um conjunto de capacitações e instituições que influenciaram significativamente sua trajetória tecnológica.

Nesse contexto, o processo de inovação na carcinicultura é estruturado no âmbito de complexos arranjos produtivos promotores de aprendizado, da geração de conhecimento e de oportunidades tecnológicas. Isso faz com que a capacidade inovativa das empresas esteja relacionada à interação dos agentes produtivos com o contexto institucional em um complexo processo socioeconômico, político e cultural. Nessa perspectiva, as mudanças tecnológicas estão associadas à experiência dessas empresas, o que a torna um processo específico às circunstâncias locais. Assim, a sucessão de êxitos e fracassos dos agentes econômicos envolvido nesse processo produtivo determinou a maneira pela qual interagem e realizam a aprendizagem e a inovação, tratando-se, portanto, de um processo cumulativo que pode, em uma certa sequência, produzir rendimentos crescentes de aprendizado (FIGUEIREDO, 2010; ROCHA, 2013). Para Figueiredo op. cit. e Dosi (1982, 2006), os agentes que utilizam e transformam as tecnologias seguem determinados padrões evolutivos chamados de trajetória tecnológica, definida como o conjunto de atividades implementadas para a solução de um problema no âmbito de um certo paradigma tecnológica. Essa solução, na maioria das vezes, resulta em inovações.

Embora o Brasil seja o terceiro produtor de camarão da América Latina e tenha demostrado avanços tecnológicos, ainda se observam alguns gargalos na gestão e na regulação do setor. Além disso, existem fragilidades institucionais que limitam a geração de inovações sustentáveis ambientalmente ao longo de sua trajetória tecnológica. Existem, contudo, alguns estudos que tratam do processo de inovação na carcinicultura; porém, são abordagens que focam uma localidade específica, como as pesquisas de Lopes e Baldi (2013), abordando a estratégia como contexto interfirma, combinando a perspectiva da imersão social e a teoria institucional; e o estudo de Freire e Baldi (2014), que realizaram uma análise das relações sociais entre agentes privados e públicos e suas interferências na geração de inovação. Ambos os estudos focam na análise de caso da carcinicultura do estado do Rio Grande do Norte no Brasil. São destaque, também, o trabalho de Natori et al. (2011), que fazem uma análise dos 
avanços tecnológicos dos sistemas agroindustriais do camarão marinho mundial. Enquanto Tahim e Araújo $(2012,2014,2015)$ analisaram o sistema de inovação e a inserção em cadeias globais de produção dos arranjos produtivos locais (APLs) de cultivo de camarão no Nordeste brasileiro.

Apesar das contribuições anteriores, considera-se fundamental a análise da trajetória tecnológica da carcinicultura do Nordeste brasileiro, por ainda não ter sido devidamente estudada. Desse modo, será possível compreender como ocorrem, especificamente, a dinâmica da inovação ambiental ao longo de sua trajetória tecnológica. Neste sentido, o objetivo deste trabalho é realizar uma análise da trajetória tecnológica da indústria de cultivo de camarão no Nordeste brasileiro e suas implicações ou limitações para a adoção de inovações sustentáveis ambientalmente. Essa análise é realizada em uma perspectiva neo-schumpeteriana. Os resultados do estudo podem auxiliar na definição das estratégias de investimentos em programas de pesquisa tecnológica e na orientação de políticas públicas para o desenvolvimento sustentável da carcinicultura no Brasil.

O artigo está organizado em sete seções, incluindo esta introdução. Na segunda seção delineia-se o setor de carcinicultura no Brasil e no mundo, com foco na produção. Na terceira seção, tem-se uma descrição dos conceitos de trajetória tecnológica e inovação ambiental no setor de cultivo de camarão. Na quarta seção estão os aspectos metodológicos do estudo. Na quinta são apresentados e discutidos os resultados da pesquisa, em que se faz a caracterização da trajetória tecnológica da carcinicultura do Nordeste brasileiro, em uma abordagem do regime tecnológico e inovação no setor. Por fim, na seção seis são feitas as considerações finais do estudo.

\section{Produção de camarão cultivado: cenário mundial e brasileiro}

No setor aquícola, o cultivo de camarão (carcinicultura) é uma das atividades que mais se expandiu no mundo nas últimas décadas, expressando taxa média de crescimento de 6,5\% no período de 2004 a 2013. Essa atividade concentra-se nos países de costas tropicais da Ásia e América Latina, os quais respondem por 99,6\% da produção mundial, na maioria, direcionada para a exportação (FAO, 2015). Essa expansão está associada a fatores como o crescente mercado internacional para o produto, o nível de rentabilidade e, principalmente, à geração das divisas para as regiões ou países produtores. Tais fatores, aliados ainda às inovações tecnológicas, atraem consideráveis investimentos, tanto públicos como privados, para o desenvolvimento da carcinicultura. Os países asiáticos são os maiores produtores de camarão cultivado, uma vez que, do total de 4,5 milhões de toneladas produzidas em 2013, $85,1 \%$ são originários desses países, destacando-se como principais produtores China $(39,2 \%)$, Indonésia $(14,0 \%)$, Vietnã $(12,1 \%)$, Tailândia $(7,4 \%)$ e Índia $(6,5 \%)$ Na América, a produção está concentrada nos países do Centro/Sul, correspondendo a $14,5 \%$ da produção mundial, destacando-se como maiores produtores deste continente Equador (47,4\%), México (18,7\%) e Brasil (10,0\%). Os dez maiores países produtores mundiais concentram, em média, $92,3 \%$ da produção total. O Brasil é o nono dessa lista, correspondendo a 1,5\% do total produzido (FAO, 2015).

Cabe destacar o fato de que essa atividade, tanto nos países asiáticos como no Brasil, é caracterizada por micros, pequenos e médios produtores concentrados em áreas específicas, formando aglomerações produtivas. Como informa Scopel (2014), as fazendas de cultivo são assimétricas, não só quanto ao tamanho, mas também com relação ao estilo e ao nível de tecnologia empregada. Parte delas explora áreas inferiores a dois hectares e trabalha de forma quase artesanal, utilizando-se de pacote tecnológico, ou seja, empregando técnicas de manejo e outros mecanismos predeterminados e de fácil aprendizado. Da mesma forma, existem cultivos que exploram grandes áreas com uso de alta tecnologia. Outra característica da carcinicultura é a predominância de apenas duas espécies cultiváveis, o camarão branco ( $P$. vannamei) originário do Pacífico e que se adapta bem em diversos lugares, inclusive nos países asiáticos, e o camarão tigre negro (P. monodon) cultivado na Ásia.

O Brasil, com seu extenso litoral, possui grandes reservatórios de água doce e condições ambientais favoráveis, além de espaços disponíveis, mão de obra relativamente barata e um crescente mercado interno. Desse modo, o país teve êxito no desenvolvimento da aquicultura, expandindo a uma taxa média de $22,5 \%$ nos últimos três anos; assim, em 2013, a produção aquícola chegou a $476.512 \mathrm{t}$, das quais $66 \%$ são peixes e $25 \%$, 
camarões (MPA/IBGE, 2013). As principais espécies cultivadas no país são: tilápia - Oreochromis niloticus; tambaqui - colossoma macropomum e o camarão - Litopenaeus vannamei (BRASIL, 2012) A indústria de cultivo de camarão, no entanto, é o segmento mais organizado do setor pesqueiro nacional, obtendo maior êxito pela sua trajetória tecnológica e pelo ordenamento da cadeia produtiva, permitindo o desenvolvimento em grande escala. Embora a produção da tilápia seja maior, essa ainda é realizada de forma artesanal e de base familiar, especialmente no Nordeste brasileiro - o maior produtor.

Com efeito, a carcinicultura brasileira se configura como a atividade mais importante do setor pesqueiro para a economia nacional. Em 2012, a cadeia produtiva de cultivo de camarão gerou 1,12 bilhão de Reais e 70 mil empregos, uma vez que os requerimentos de mão de obra por unidade de área explorada são de tal ordem que o segmento se destaca, em especial no Nordeste brasileiro, como o maior ofertante de emprego permanente no setor primário da economia regional (ROCHA, 2013).

Os dados setoriais do Censo da Carcinicultura Nacional (ABCC, 2015a) demonstraram que o Brasil possui 1.545 empreendimentos, cujas estruturas produtivas mostram assimetrias, tanto no que refere a distintos tamanhos das empresas quanto ao variado poder de mercado. A atividade é marcada pela predominância de micros $(58,6 \%)$, pequenos $(15 \%)$ e médios produtores $^{5}(20 \%)$, representado $93,6 \%$ total de empreendimentos, e ainda se verifica a existência de grandes empresas $(6,4 \%)$ verticalizadas com maior poder de mercado, tanto nacional como internacional. Somente essas grandes empresas correspondem por $58,6 \%$ da área cultivada e por $58,4 \%$ da produção.

O cultivo de camarão em cativeiro está distribuído geograficamente nas regiões Sul, Norte e Nordeste do Brasil, cuja produção em 2014 foi de 85 mil toneladas, correspondendo a um valor de 1,35 milhões de Reais (TORRES, 2015). Porém, o Nordeste brasileiro é a principal região produtora de camarão nacional, verificando-se intensa concentração de produtores ao longo de suas áreas costeiras e estuarinas. Essa região produz $99,63 \%$ do camarão nacional e conta

5. Classificação de acordo com a resolução no 312/2002 do Conselho Nacional do Meio Ambiente (Conama): micro ( $<3 \mathrm{ha})$, pequenas (3-10 ha), médias (10-30 ha) e grandes produtores ( $>30 \mathrm{ha})$. com $92 \%$ do total de produtores, seguida pela região Sul $(0,37 \%)$. Embora seja produzido em todos os estados no Nordeste, o Rio Grande do Norte e o Ceará, nessa região, são os maiores produtores de camarão, concentrando o maior número de empreendimentos, com 33,2\% e 33\%, respectivamente, e responsáveis por $83,53 \%$ da produção brasileira de camarão em 2014, seguidos pelos seguintes estados: Bahia, Pernambuco, Piauí, Sergipe e Paraíba, que, juntos, representam apenas 16,10\% (TORRES, 2015; ABCC, 2015b).

A alta concentração de produtores no Nordeste está relacionada às vantagens que a região possui para o desenvolvimento da atividade, tais como: extensas áreas costeiras para o cultivo de camarão e melhores condições ambientais e sanitárias. Além do domínio das tecnologias de reprodução, larvicultura e engorda da espécie L. vannamei, por meio de processos tecnológicos desenvolvidos nas próprias empresas (ROCHA, 2013; CARVALHO et al., 2005). Essas características permitiram o adensamento da cadeia produtiva com o surgimento de várias fábricas de equipamentos, ração (com tecnologias asiática e estadunidense), fertilizantes e outros insumos laboratórios de maturação e larvicultura, centros de processamento/industrialização do camarão, favorecendo a viabilidade técnica e econômica do setor.

\section{Trajetória tecnológica, regime tecnológico e inovações ambientais}

A literatura neo-schumpeteriana enfatiza que as trajetórias que surgem de um paradigma tecnológico ${ }^{6}$ raramente são impulsionadas apenas por fatores científicos e tecnológicos externos, mas, principalmente, por fatores econômicos e políticos, fundamentais na determinação dessas trajetórias tecnológicas. Da mesma forma, o processo de seleção para a inovação ocorre num ambiente específico em que as estratégias das empresas, a qualidade das instituições técnicas e científicas, o estímulo e financiamento às inovações representam papel preponderante. Assim, a diversidade do ambiente de seleção pode explicar as distintas trajetórias tecnológicas. Ainda segundo essa corrente,

6. O paradigma é um pacote de procedimentos que orientam a investigação sobre um problema tecnológico, definindo o contexto, os objetivos a serem alcançados e os recursos a serem utilizados (DOSI, 2006). 
aprendizado é cumulativo, dependente, portanto, de trajetórias passadas, indicando que a evolução de uma empresa é determinada por competências acumuladas e pela natureza de seus ativos específicos. Tais competências mudam em função das oportunidades tecnológicas (TIGRE, 2006).

Com efeito, Tidd et al. (2008) apontam que a habilidade das empresas em identificar e explorar suas trajetórias tecnológicas depende de suas competências tecnológicas e organizacionais específicas, além da dificuldade que as empresas concorrentes têm de imitá-las. Esse fato explica por que algumas empresas são diferentes e a forma como mudam ao passar do tempo. O conceito de trajetória tecnológica pode ainda ser aplicado, conforme esses autores, como as tecnologias, controladas pelos limites do conhecimento, ou ainda pelas empresas, dirigidas por meio dos seus limites cognitivos. Dosi $(1982,2006)$ define trajetória tecnológica como o conjunto de atividades implementadas para a solução de um problema definido no âmbito do paradigma tecnológico. Neste sentido, o conceito de trajetória tecnológica está delimitado por programas de pesquisa tecnológica e pelo ambiente de seleção, os quais direcionam a resposta ao paradigma tecnológico (DUNHAM; BOMTEMPO; ALMEIDA, 2006).

As trajetórias tecnológicas têm características próprias, em decorrência de transpassarem certos estágios evolutivos. No início de sua evolução, por exemplo, uma trajetória tecnológica demonstra um grande espectro de possibilidades. Assim, é nesse estágio que costumam competir diversos sistemas tecnológicos, apresentando potenciais para dominação de um sobre o outro. Existem, portanto, vários caminhos possíveis, e cada um deles constitui um determinado conjunto de tecnologias inter-relacionadas (CARVALHO; FURTADO, 2013).

As trajetórias naturais são específicas e referem-se a uma tecnologia particular relacionada ao regime tecnológico, que define os padrões inovativos de acordo com as condições de oportunidade, apropriabilidade e cumulatividade das propriedades ligadas à natureza e à transmissão do conhecimento. A oportunidade refere-se à capacidade de um setor de originar novas tecnologias; a apropriabilidade relaciona-se ao grau de proteção das inovações contra as imitações, e a cumulatividade pode ser entendida pelas inovações sequenciais com melhoramentos graduais, ou seja, a capacidade de inovar com base em inovações passa- das e áreas correlatas. Enquanto isso, o conhecimento tecnológico é definido segundo seus graus de especificidade, codificação e complexidade (MALERBA; ORSENIGO, 1996; BRESCHI; MALERBA; ORSENIGO, 2000).

O avanço ao longo de uma trajetória tecnológica significa o aperfeiçoamento de atributos técnicos e econômicos desejáveis de um produto, equipamento, ferramenta ou dispositivo, reduzindo, assim, as opções excludentes entre esses dois atributos. Essa trajetória tecnológica está, portanto, relacionada ao caminho tecnológico percorrido, constituindo um conjunto de passos na direção do desenvolvimento tecnológico, representado por mudanças tecnológicas, as quais podem ser inovações incrementais e radicais (FREIRE; BALDI, 2014). As primeiras referem-se a qualquer tipo de melhorias e modificações em produtos, processos ou organização da produção; já a segunda trata do desenvolvimento e da introdução de um novo produto, processo ou nova forma organizacional da produção, podendo causar saltos descontínuos na tecnologia (FREEMAN, 2005; TIGRE, 2006).

Para Carvalho e Furtado (2013), os países em desenvolvimento assumiram uma posição secundária diante das novas tecnologias, em que os receptores - um grupo importante de empresas - realizam um esforço tecnológico fundamental, voltado, principalmente, para um determinado tipo de inovação com natureza incremental. As inovações são introduzidas preferencialmente sobre bases técnicas maduras, conformando um tipo de trajetória tecnológica específica a esses países. A trajetória tecnológica das empresas, entretanto, apoiada em inovações incrementais, envolve uma série de estratégias e práticas da gestão que, embora em muitas delas passem despercebidas, podem trazer benefícios, como: custos menores de produção, novas rotinas e procedimentos organizacionais, novas características aos produtos e serviços, diferente das inovações radicais que podem causar altos impactos mercadológicos (DODGSON et al., 2008).

Dosi, Marengo e Pasquali (2006) assinalam que fatores importantes para a busca de inovações estão relacionados com as características do conhecimento e da solução de problemas, ou seja, dependem da acumulação prévia de conhecimento. Nesta perspectiva, o processo inovativo é fortemente induzido pelo paradigma tecnológico e suas trajetórias e exprime dinâmica e regras próprias. Isso porque alguns aspectos do 
processo de inovação estão bem estabelecidos, como as atividades de pesquisa e desenvolvimento, o aprendizado por interação/acumulação e a mudança técnica, considerando o papel fundamental dos fatores econômicos, institucionais e sociais.

De certa forma, esse referencial possibilita a compreensão do processo inovativo em seus variados níveis e especificidades, tendo por base alguns conceitos, como aprendizados, interação, competências, complementaridade, seleção, path-dependence etc., enfatizado os aspectos regionais e locais. Desse modo, o processo de inovação é caracterizado como interativo, realizado por via da contribuição de vários agentes socioeconômicos que detêm diversos tipos de informações e conhecimentos. Esse processo apresenta diferentes aspectos, com caráter social e coletivo. Assim, a combinação dos avanços tecnológicos com os conhecimentos adquiridos e as necessidades do mercado resultam em inovação, tanto em produtos e processos, como em termos de mudanças de base tecnológica e organização de empresas, setores ou países (CASSIOLATO; LASTRES, 2005; OCDE, 2015).

O caráter cumulativo do processo inovativo delimita o impacto das inovações sobre o potencial das inovações futuras. Ao se observar esse processo intensamente cumulativo, as empresas inovativas que obtiverem sucesso no período corrente vão expressar probabilidade de sucesso mais elevada no período futuro, quando comparadas às outras que não obtiveram êxito. O processo de inovação cumulativo está relacionado àqueles ambientes tecnológicos que representam rendimentos crescentes das atividades de pesquisa (VIERIA FILHO, 2009).

No que concerne, entretanto, ao setor da carcinicultura, a preocupação com a sustentabilidade é cada vez maior na agenda de inovação, na busca de processos, produtos e serviços novos ou mais sustentáveis para garantir a segurança e a redução de impactos ambientais. Na perspectiva de Tidd et al. (2008), as inovações conectadas a fatores de sustentabilidade geralmente possuem implicações sistêmicas e enfatizam a necessidade de gerenciamento integrado. Essas inovações surgem da preocupação em contextos sociais, políticos e culturais complexos e oferecem alto risco de fracasso se forem desconsiderados tais elementos de demanda. Por conseguinte, tanto o ambiente econômico como o político afetam a sua trajetória tecnológica. Assim, o processo de inovação registra uma dinâmica própria que direciona o desenvolvimento tecnológico de uma empresa ou setor. Sendo, portanto, nessa perspectiva que se define a trajetória tecnológica perseguida pelo setor em análise, para, então, compreender as características, mudanças e implicações sobre o seu processo inovativo.

\section{Metodologia}

Para a elaboração do estudo sobre a trajetória tecnológica da carcinicultura do Nordeste brasileiro, realizou-se uma pesquisa quantiqualitativa, de caráter descritivo e explicativo, delineando-se como um estudo de caso. As informações foram obtidas empregando-se duas fontes de dados. A primeira relacionada à base de dados da FAO, da Associação Brasileira de Criadores de Camarão (ABCC) e do Ministério da Pesca e Aquicultura (MPA). A segunda, a partir de entrevistas semiestruturadas, realizada em 2014, com diversos agentes que compõem o sistema industrial do cultivo de camarão do Nordeste brasileiro, abordando aspectos relacionados ao desenvolvimento tecnológico com foco na identificação de sua trajetória; aos processos de aprendizado e de inovação, bem como o regime tecnológico. Assim, foram abordadas as principais empresas da cadeia produtiva (fazendas de cultivo, empresas de processamento, laboratório de pós-larvas), além de entrevistas com as instituições de ensino e pesquisa da região, associação de classe, órgãos governamentais e de regulação e controle. Do universo de 1.429 empresas instaladas na região Nordeste, determinou-se uma amostra, de forma aleatória, de 150 empreendimentos para a realização das entrevistas, considerando margem de erro de 5\% e nível de significância de 95\% (BARDIN, 2009). Na pesquisa, contou-se, ainda, com observações do setor ao longo de cinco anos (2009 a 2014).

\section{Resultados e discussões}

\subsection{Trajetória tecnológica}

A trajetória tecnológica que marca o desenvolvimento da carcinicultura no Brasil é determinada por sistemas produtivos e inovativos complexos, formado por um conjunto de capacitações e instituições que 
proporcionam mudanças tecnológicas importantes no setor ao longo de sua trajetória. Conforme analisado, a constituição de uma trajetória tecnológica pode ser moldada pela interação da pesquisa básica e aplicada, com maior intensidade, no primeiro momento, nos conhecimentos fundamentais e, posteriormente, nas soluções dos problemas de natureza técnica (DOSI, 2006; VIEIRA FILHO, 2009).

Freire e Baldi (2014) definem a trajetória tecnológica do cultivo de camarão, no Rio Grande do Norte, em quatro fases distintas: introdução do período tecnológico (973-1980); intensificação das pesquisas (1981-1991); adaptabilidade da tecnologia (1992-2003) e crise tecnológica (2004-2011). Essas fases se estendem na carcinicultura de todo o País. A primeira fase (1973-1980) se dá com a implantação de projetos pioneiros no Nordeste brasileiro, com a introdução e a adaptação da espécie P. japonicus, de origem asiática, em áreas costeiras abandonadas pela atividade salineira. Nessa fase, a tecnologia foi aprimorada e validada, passando-se a utilizar um pacote tecnológico com a tentativa de adaptação às condições da região. Essa fase foi de iniciativa do governo do Rio Grande do Norte, por meio da criação do "Projeto Camarão", com o objetivo de substituir a extração de sal pelo cultivo de camarão. Esse projeto teve apoio de programas de financiamento do Banco do Brasil (BB), Banco Interamericano de Desenvolvimento (BID) e Banco de Desenvolvimento do Rio Grande do Norte (BDRGN). Esse fato também foi observado em Rocha (2006b); Natori et al. (2011); Freire e Baldi (2014). Conforme pode-se perceber, essa estratégia inicialmente consistia em se qualificar como um comprador de tecnologias externas. Essas tecnologias vinham na forma de aquisição de equipamentos, matéria-prima (pós-larvas e reprodutores) e contratação de consultorias e visitas técnicas a países onde o cultivo era desenvolvido. O esforço tecnológico dirigia-se também para a formação de recursos humanos, com a participação das universidades de alguns estados do Nordeste, como Rio Grande do Norte, Ceará e Pernambuco.

Com isto, têm-se os primeiros empreendimentos de carcinicultura no Nordeste para exploração comercial; entretanto, esta iniciativa não logrou êxito, pois a espécie $P$. japonicus não se adaptou às condições de elevadas salinidades e temperaturas da região. Neste período, muitos projetos fracassaram, tornando sua exploração inviável economicamente. Isso levou à busca de opções, dando início à segunda fase do desenvolvimento da carcinicultura na região. A segunda fase (1981-1991) ocorreu com intensidade de pesquisa, tanto na inciativa privada quanto pública, pois, devido ao insucesso com a espécie exótica, a disponibilidade da infraestrutura de laboratório, as fazendas de camarão já instaladas e o conhecimento acumulado dos técnicos permitiram a continuação dos experimentos voltados para as espécies nativas. Essas pesquisas foram realizadas por instituições de pesquisa no Ceará e no Rio Grande do Norte. O processo de produção, no entanto, era bastante rudimentar, com base na tentativa e no erro, ou seja, no "aprender fazendo"7.

No final dos anos 1980, a Universidade Federal de Santa Catarina realizou experimentos, na tentativa de obter a reprodução em cativeiro de espécies nativas, conseguindo, inclusive, produzir as primeiras pós-larvas em laboratório da América Latina. Neste período, ocorreu também a primeira tentativa de implantação do sistema semi-intensivo de criação de camarão em cativeiro. Isto representou um salto tecnológico em sua trajetória, resultando, inclusive, em inovações radicais (produção de pós-larvas em cativeiro). Desse modo, foram obtidos alguns avanços, tanto na reprodução e na larvicultura quanto no manejo de água e solo nos viveiros. O desempenho produtivo dessas espécies, contudo, não foi suficiente para garantir a rentabilidade dos empreendimentos.

Inicia-se, então, a terceira fase da trajetória tecnológica da carcinicultura (1992-2003), com a busca de opções ao cultivo das espécies nacionais. Foram realizadas importações de reprodutores e pós-larvas da espécie Litopenaeus vannamei, originária do Pacífico, que se adaptou muito bem às condições ambientais brasileiras. Uma das primeiras fazendas de cultivo a utilizar essa espécie localizava-se na Bahia, propagando-se depois para o restante dos empreendimentos no Nordeste. Essa espécie já era cultivada com grande êxito no Equador e em outros países do Ocidente. Neste período, algumas empresas da região contrataram técnicos de países como Peru, Equador e Japão para realizarem P\&D, gerando spillover, facili-

7. Os cultivos dependiam totalmente do meio ambiente natural para captura das espécies. Pós-larvas e reprodutores eram capturados no mar aberto ou nas zonas de mangues para o desenvolvimento em laboratório e o armazenamento para as culturas em viveiros. Esse procedimento também estava sujeito a críticas relacionadas às questões ambientais. 
tando, assim, a adoção e o domínio da tecnologia de cultivo, reprodução e larvicultura da referida espécie no Brasil. Com isto, surgiram diversos laboratórios que passaram a ofertar regulamente pós-larva para o mercado, fazendo com que o Brasil se tornasse autossuficiente (CARVALHO et al., 2005; LOPES; BALDI, 2013). Surgiram também fábricas de ração com tecnologias asiática e dos EUA voltadas para alimentação do camarão e novos equipamentos, permitindo, assim, viabilidade técnica e econômica dos cultivos semi-intensivos.

A intensificação dos cultivos no Nordeste brasileiro, nos anos 1990, só foi possível com os avanços tecnológicos na produção e reprodução de pós-larva, na industrialização de ração balanceada, no manejo da qualidade da água, na engenharia dos projetos das fazendas, inclusive com o desenvolvimento de bandejas fixas para alimentação, caiaques com hidrodinâmica específica, dentre outras inovações (ROCHA, 2013). Isso, conforme observado, resultou no processo cumulativo de mais conhecimentos, levando à revitalização das fazendas, que passaram a obter índices de produtividade e rentabilidade bastante elevados, atraindo outros grandes investidores para a atividade. Todos estes fatores contribuíram de forma significativa para o aumento da produção e expansão das áreas cultivadas, permitindo que o Brasil se tornasse um dos principais produtores de camarão cultivado no mundo.

Na quarta e última fase da trajetória do setor (20042011), no entanto, esse dinamismo, em termos de inovações tecnológicas observado na fase anterior, foi comprometido, visto que, nos últimos anos, no Brasil, mesmo com o aumento de produtividade, principalmente entre os pequenos e médios produtores, não foram verificadas melhorias significativas na tecnologia de cultivo, em assistência técnica e até mesmo na capacitação de recursos humanos. Isso também foi constatado por Wurmann e Madrid (2006), quando acentuam que os avanços nos processos produtivos se sucedem de forma relativamente lenta e gradativa e referem-se a técnicas de manejo dos cultivos e/ou utilização de novos insumos, materiais e equipamentos. De modo geral, tais inovações se restringem aos aspectos incrementais das principais etapas do processo produtivo - larvicultura, engorda e processamento.

A adoção de inovações, nas quatro fases da trajetória tecnológica da carcinicultura no Nordeste do Brasil, pode ser representada em uma curva "S", que descreve o uso de tecnologias em função do tempo (Figura 1).

Figura 1. Fases da trajetória tecnológica do cultivo de camarão no Nordeste do Brasil

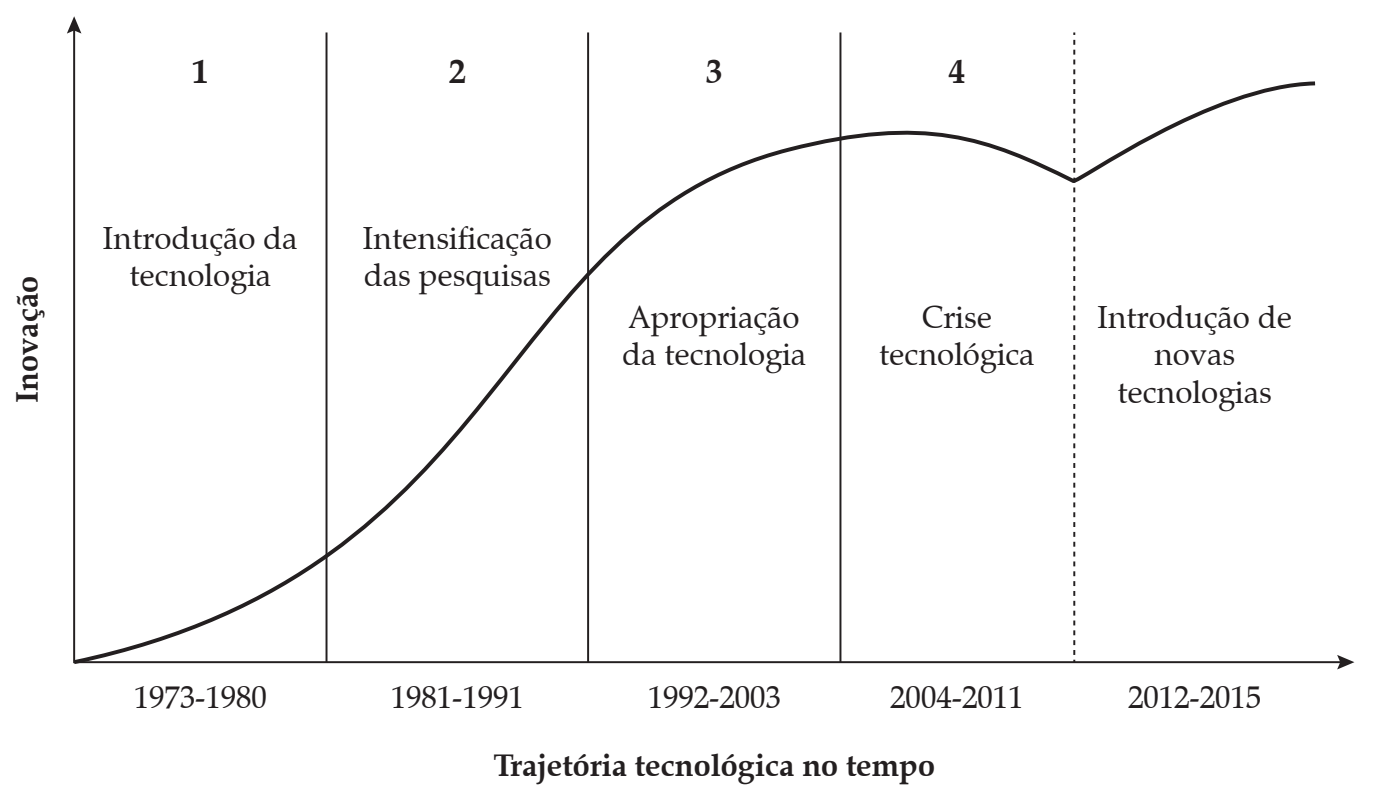

Fonte: Elaboração própria. 
Observa-se, ainda, que, devido à procura cada vez maior pela segurança alimentar. Assim, os compradores passam a exigir certos pré-requisitos, como a rastreabilidade dos produtos desde sua origem e a exigência de certificação. Esses procedimentos foram impulsionados principalmente pelos problemas sanitários e ambientais na cadeia produtiva. Tais fatores, aliados à ação antidumping promovida pelos Estados Unidos, a problemas climáticos e limites biológicos do sistema de cultivo, culminando em uma crise tanto econômica como tecnológica que, de acordo com Freire e Baldi (2014) e Lopes e Baldi, (2013), resultou na estagnação do setor em termos tecnológicos, considerando-se que os padrões adotados chegam a um limite de eficácia.

No entanto, atualmente, é possível observar que está surgindo uma nova etapa dessa trajetória - com potencial para tornar-se uma nova trajetória tecnológica. Nessa nova etapa observa-se o apoio dos setores público e privado, representados, respectivamente, pela Associação Brasileira dos Criadores de Camarão (ABCC), Ministério da Pesca e Aquicultura (MPA) e instituições de pesquisa e ensino, com destaque para o Centro de Tecnologia do Camarão na Região Nordeste e Rede de Carcinicultura do Nordeste

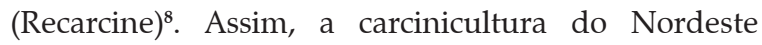
brasileiro passou a ter um novo impulso com o lançamento, em 2012, pelo MPA/ABCC, de amplo e vigoroso plano regional de capacitação, intitulado "Projeto de Desenvolvimento Tecnológico com Boas Práticas de Manejo e Biossegurança para a Carcinicultura do Nordeste Brasileiro", direcionado a todos os agentes envolvidos no segmento dos principais elos da cadeia produtiva do cultivo de camarão, como laboratórios de pós-larvas, fazendas de engordas, centros de processamentos e até fabricas de ração.

Em adição ao início dessa nova etapa, uma comissão de técnicos e empresários do setor realizou, em 2013, visitas técnicas aos principais países asiáticos produtores de camarão, com a finalidade de adquirirem informações e conhecimentos dos avanços tecnológicos na produção intensiva do camarão L. vannamei, que poderão ser adotados no Brasil. Além desses fatores, já se observam fazendas adotando o cultivo orgânico, o policultivo (cultivo consorciado de tilápia e camarão)

8. Rede de pesquisa multidisciplinar sobre o cultivo de camarão, composta por pesquisadores de diferentes áreas do conhecimento em vários estados do Brasil. e em fase de implantar um sistema de rastreabilidade dos cultivos, bem como de implantação de sistema de bioflocos ${ }^{9}$, mencionando-se, ainda, a consolidação do mercado interno para o produto. Essas ações, de fato, poderão causar transformações significativas na trajetória tecnológica da carcinicultura do Nordeste brasileiro.

\subsection{Regime tecnológico e processo inovativo}

Para compreender o complexo arranjo produtivo da carcinicultura do Nordeste brasileiro em termos do processo produtivo e inovativo, é necessário aprofundar o conhecimento das especificidades do regime tecnológico desse segmento, embora parte destas especificidades tenha sido tratada no item anterior em uma perspectiva histórica. De acordo com os resultados das entrevistas e as observações realizadas, percebeu-se que tal regime, no segmento de cultivo de camarão, está correlacionado às condições específicas de oportunidade, apropriação, cumulatividade e propriedades da natureza do conhecimento, condicionando as estratégias inovativas das empresas. Apesar disso, percebe-se que, ao longo de sua trajetória, o foco maior está na oportunidade e na cumulatividade, baseado no processo de aprendizado local e na acumulação de conhecimento, que ocorreu tanto pelo desenvolvimento de P\&D quanto pela absorção e adaptação de tecnologias externas.

Nesse contexto, considerando-se as tecnologias em curso, o sistema produtivo de camarão da região Nordeste expressa variado nível tecnológico, de acordo com os tamanhos e estilos das propriedades, conforme já citado, cujas tecnologias, utilizadas no processo produtivo, variam de acordo com o tipo de sistema de cultivo - extensivo, semi-intensivo e intensivo. O sistema semi-intensivo é o que predomina na região Nordeste, embora se verifique o sistema intensivo em algumas fazendas de cultivo em alguns estados dessa região. Os sistemas semi-intensivo e intensivo são utilizados, na sua maioria, nas grandes e médias empresas, em que

9. O sistema de cultivo em bioflocos (Biofloc Technology System - BFT) praticamente não realiza renovação da água e usa microrganismos como alimento natural, reduzindo a utilização de rações. Esse sistema melhora os níveis de produtividade e de biossegurança em comparação com os sistemas tradicionais (WASIELESKY; KRUMMENAUE, 2013). 
se verificam mudanças nos processos produtivos que vão desde o uso de ração balanceada com ajuste de consumo, correção e tratamento do solo dos viveiros, melhores controles dos parâmetros físico-químicos da água e preocupação com o tratamento de efluentes orientada para a sustentabilidade ambiental (ROCHA, 2006; BORBA; NOGUEIRA, 2013). Uma tendência que se observa, no entanto, é o surgimento do sistema extensivo, adequado ao cultivo de camarão orgânico que vem se expandido na região.

Cabe ressaltar, contudo, que, de acordo com os resultados das observações e entrevistas, as empresas de grande porte, e algumas de médio, são as que mais se beneficiam dessas tecnologias, ao contrário das pequenas, que têm dificuldades para incorporá-las, pelo fato de essas tecnologias serem intensivas em capital e também pela limitação de área. Além disto, as pequenas empresas são menos organizadas, produzem de forma quase artesanal, utilizando-se de pacote tecnológico, ou seja, aplicando técnicas de manejo e outros mecanismos predeterminados e de fácil aprendizado, contribuindo para fragilizar as barreiras à entrada e à saída. Isso mostra a necessidade do desenvolvimento de tecnologias mais apropriadas às condições das MPEs, levando-se em consideração questões relacionadas aos custos e às limitações específicas do setor.

As grandes empresas, na sua maioria, são verticalizadas, realizando mais de uma etapa do segmento da cadeia produtiva. Algumas delas atuam como empresas âncoras, subcontratando ou arrendando pequenas empresas desativadas, nos arranjos produtivos locais, para a realização de parte do processo produtivo, restrita principalmente à etapa de engorda do camarão. Estas fornecem às pequenas empresas pós-larvas, assistência técnica, capital, outros insumos e a comercialização, uma vez que dependem da produção dos pequenos e médios produtores para cumprir seus compromissos comerciais (ORMOND et al., 2004; CARVALHO et al., 2005). Esse tipo de relação tem se aprofundado com o incentivo da ABCC nos últimos anos. Essas ações são, portanto, uma oportunidade para aumentar a competitividade do segmento.

Analisando-se o processo produtivo do camarão, é possível observar que são envolvidas diversas empresas, atuando em distintas etapas da cadeia produtiva, com destaque para os três segmentos principais de empresas, estritamente relacionados - o laboratório de maturação da larvicultura, onde são produzidas as pós-larvas; as fazendas de engorda, onde ocorre o ciclo de desenvolvimento do camarão, e os centros de processamento, que beneficiam a produção, passando pela classificação, embalagem e congelamento para os mercados interno e externo. Esses segmentos estão conectados para frente e para trás com outras grandes indústrias de insumos (ração, fertilizantes nitrogenados e fosfatados, probióticos etc.) e equipamentos (geradores, bombas, motores, medidores de parâmetros físico-químicos, água e outros insumos/ equipamentos que fazem parte do processo do camarão), distribuição, embalagem e de outros serviços. Observa-se, também, com base nas entrevistas, que a organização do processo da carcinicultura é definida em sentido amplo, envolvendo não apenas as atividades a montante e a jusante dos três principais segmentos produtivos, como também um amplo sistema de pesquisa, ciência e tecnologia, embora nem sempre de forma articulada.

Desse modo, percebe-se que as inovações relevantes na carcinicultura ocorrem ao longo de toda a cadeia produtiva regional, ou seja, não só no bloco dos fornecedores de insumos tecnológicos, máquinas e equipamentos (que compreende as inovações mecânicas, químicas e biológicas, tecnologia de nutrição, organizacionais entre outras), mas também nos laboratórios de pós-larvas, na fazenda de engorda e no processamento, envolvendo inovações relacionadas à produção e à reprodução do camarão (melhoramento genético, desenho e engenharia de projetos, biossegurança, mais recentemente, biotecnologia). Portanto, nota-se que há certa complementaridade setorial e uma co-evolução da produção e do desenvolvimento de novas tecnologias. Os estudos empíricos de Malerba e Orsenigo (1996), Breschi, Malerba e Orsenigo (2000) e Vieira (2009) mostram que a estrutura institucional para o desenvolvimento da inovação é muito complexa dentro de um setor econômico, pois varia significativamente entre o conjunto dos demais setores, fator observado na carcinicultura.

Cada etapa da cadeia produtiva apresenta atividades bastante específicas e complexas, envolvendo áreas diversas de conhecimento, revelando um caráter interdisciplinar e propício ao surgimento de novas disciplinas/conhecimento, proporcionando mudanças técnicas e tecnológicas desse setor. A Figura 2 apresenta a complexidade interdisciplinar do setor de cultivo de camarão na região Nordeste do País. 
Figura 2. Interdisciplinaridade do setor de cultivo de camarão: novas tendências

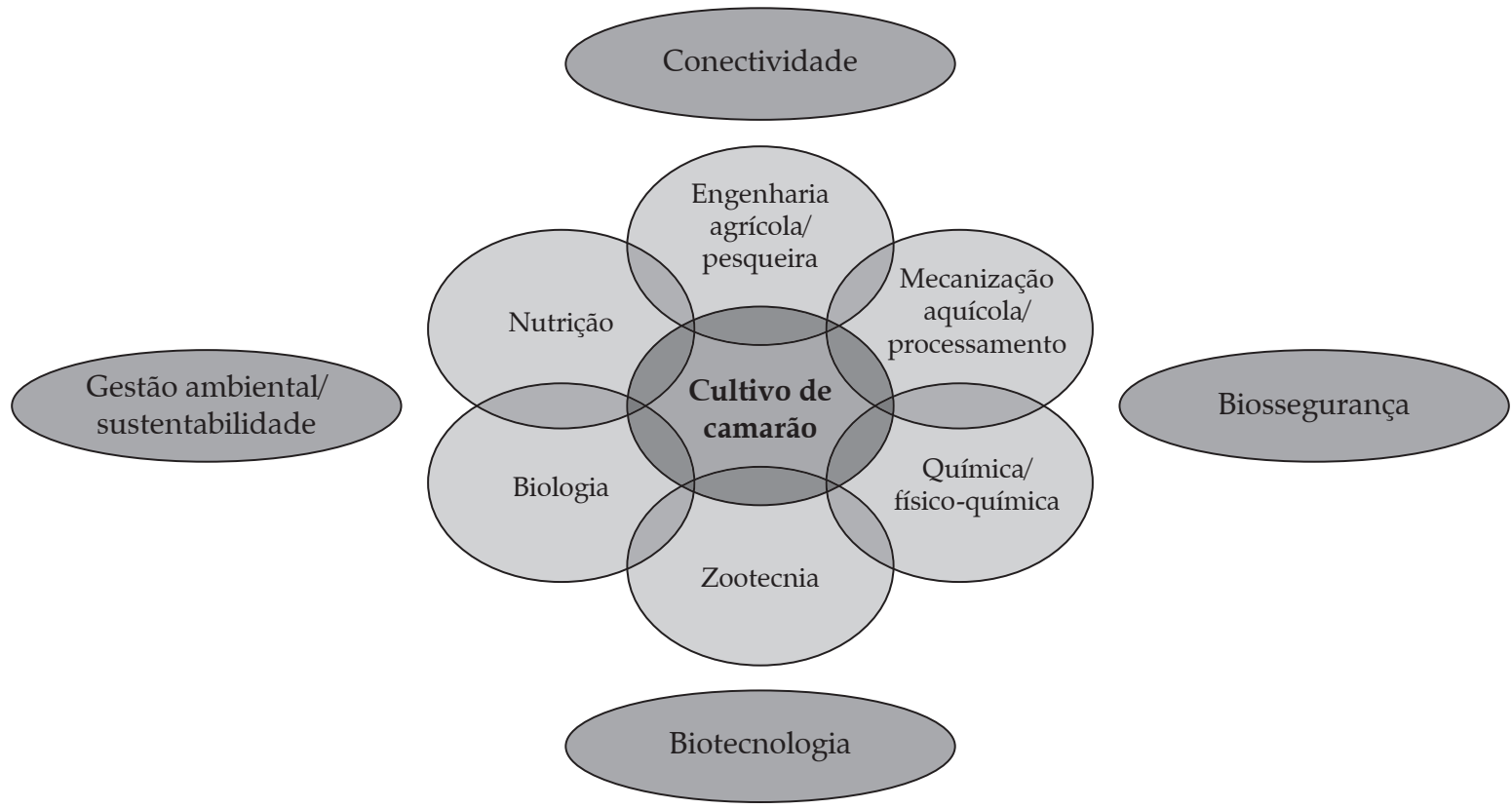

Fonte: Elaboração própria.

A interação entre essas diversas áreas do conhecimento possibilita o surgimento de tecnologias emergentes, gerando novos processos no manejo dos cultivos (uso de bioflocos) e produtos (camarão orgânico, pós-larvas mais resistentes a patógenos), além de agregar novas propriedades ao processamento do camarão, podendo abranger, ainda, a cadeia produtiva do cultivo de camarão como um todo devido à sua interdisciplinaridade.

\subsection{Inovações ambientais}

De acordo com os resultados das entrevistas e observações junto aos diversos agentes, o processo de inovação na carcinicultura, que define tanto a geração como a adoção, bem como os parâmetros da difusão tecnológica, é constituído no interior de complexos arranjos produtivos, interligados, mediados por instituições promotoras do conhecimento, como centros de pesquisa, universidades, entidades de classe e órgãos reguladores. Desse modo, a capacidade produtiva e inovativa das empresas desses arranjos é determinada não só pelas competências e habilidades adquiridas internamente, mas também pela existência de outros elementos externos que atuam como fatores determinantes para o aprendizado, a produção e a incorporação de conhecimentos e da geração e adoção de inovação. Esses aspectos foram levados em consideração ao se analisar o sistema produtivo da carcinicultura do Nordeste. Dessa forma, o debate sobre a incorporação de inovação nas empresas pesquisadas baseia-se numa visão mais ampla do processo de inovação, destacando-se a incorporação de inovações que vão desde a utilização de bandejas fixas para alimentos produzidos artesanalmente até processos mais complexos e dinâmicos, envolvendo melhorias nas técnicas de cultivo, nutrição e tecnologia de reprodução, além de mudanças no layout das fazendas para a incorporação de lagoa de sedimentação e tanques berçários, policultivo e camarão orgânico, por exemplo.

As empresas analisadas denotam certa heterogeneidade em termos de capacitação produtiva e inovativa, considerando os segmentos de empresas que participam da cadeia regional. Essa heterogeneidade é evidenciada pelo grau de atualização tecnológica das grandes e de parte das médias empresas, em contraste com as pequenas empresas, que são maioria na região e com pouco dinamismo inovativo, operando de forma 
quase artesanal. Desse modo, observou-se que as tecnologias utilizadas pelas grandes e parte das médias empresas são mais complexas e avançadas.

As principais inovações adotadas pelas empresas entrevistadas na região Nordeste referem-se a processos, com 75,8\% do total da amostra, especialmente para as grandes e as médias empresas, e à incorporação de equipamentos, com 72,6\% do total de entrevistados, com maior destaque para as pequenas empresas (Figura 3). Estes processos, conforme observado, estão associados a melhorias no controle e nas práticas de manejo dos cultivos, envolvendo alguns procedimentos que vão desde a aquisição da pós-larva até a etapa de despesca e transporte do produto para as empresas processadoras, como o melhor controle das condições físico-químicas da água dos viveiros, melhorias nas práticas do arraçoamento e no tipo de alimento utilizado, preparo e manejo dos viveiros e cuidados sanitários. Os equipamentos são relacionados à aquisição de aeradores, monitores de água e principalmente de bandejas fixas para alimentação, visto que esses equi- pamentos tinham sua utilização restrita pela maioria das pequenas e parte das médias empresas que operavam de forma artesanal.

A introdução de boas práticas de manejo e biossegurança (32,6\% do total da amostra) é adotada principalmente pelo amplo programa de treinamento e capacitação. Essa ação contou com o apoio de instituições públicas e associação de produtores (ABCC), tendo início em 2013, com tendência de mais produtores adotarem, em razão das exigências dos consumidores que buscam segurança alimentar. A procura de novos mercados também representou um percentual bastante significativo $(66,3 \%$ do total de entrevistados). Esse resultado está mais relacionado à queda das vendas para o mercado externo, que forçou a sua substituição pelo mercado interno, do que à adoção de estratégia de marketing para a conquista de novos mercados.

Para as inovações relacionadas às mudanças organizacionais, observou-se que ocorreram com maior intensidade nas grandes empresas. Destacam-se como

Figura 3. As inovações realizadas pelas empresas de cultivo de camarão entrevistadas na região Nordeste de Brasil (2011-2013)

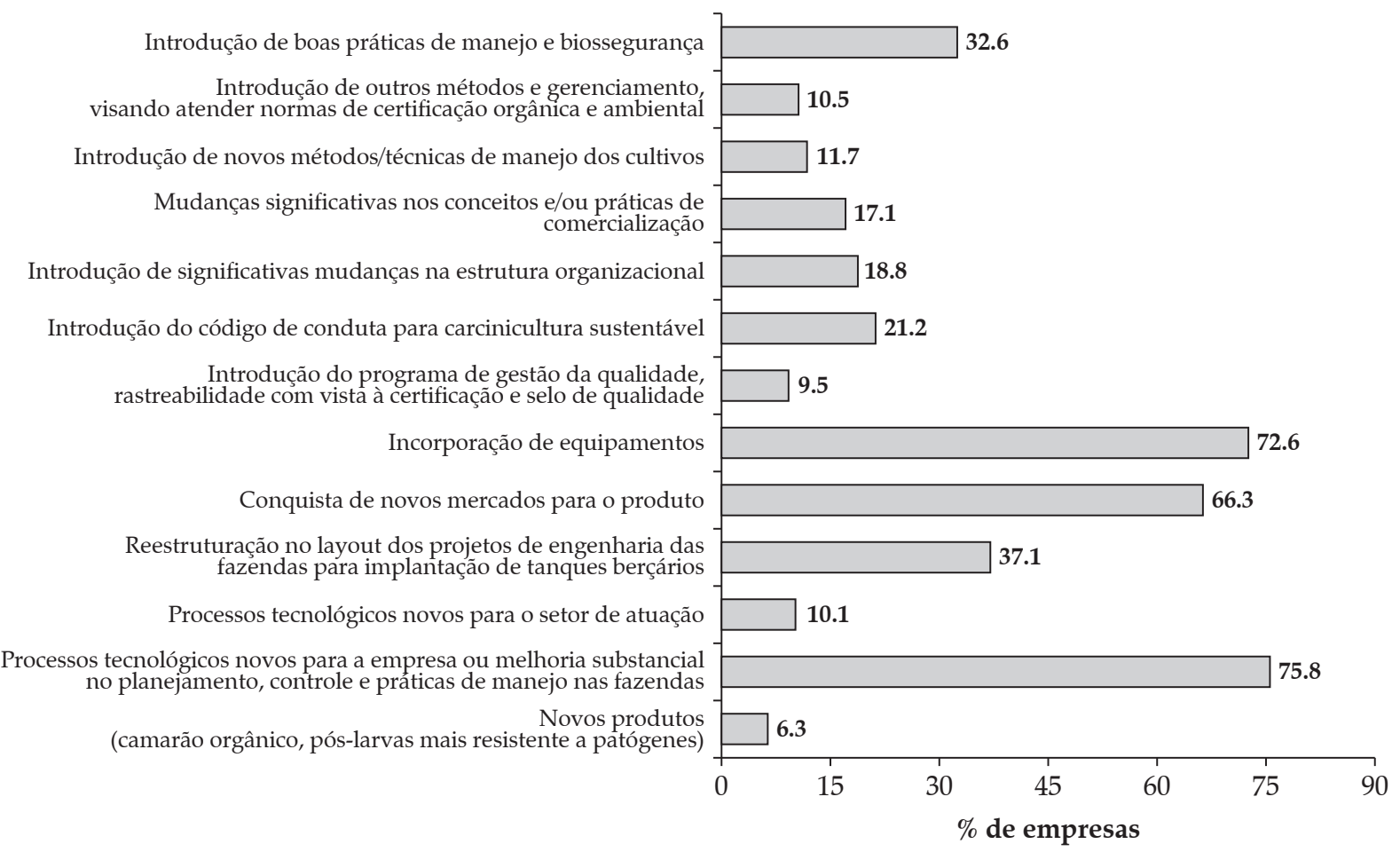

Fonte: Elaboração própria, a partir dos dados da pesquisa de campo. 
principais inovações: procedimentos-padrão de controle sistemático de qualidade, estabelecidos pelo código de conduta para a carcinicultura sustentável, seguidos pela implantação de programas da gestão de qualidade, certificação orgânica e ambiental.

Cabe ressaltar que, entre os três principais segmentos da cadeia produtiva do camarão, o laboratório de larvicultura é o mais intensivo em tecnologia. A incorporação de inovações na etapa de reprodução e de larvicultura envolve o desenvolvimento de melhorias permanentes nas técnicas de reprodução e de cultivo de pós-larvas e na busca de variedades mais resistentes. Essas inovações ocorrem com a utilização da base de conhecimentos resultante de atividades de pesquisa e desenvolvimento (P\&D) desenvolvidas nos próprios laboratórios. Na etapa de beneficiamento do camarão, as inovações, na sua maioria, são também de processos, estando associadas à incorporação de equipamentos incrementais em determinadas etapas do processamento e Sistema de Análise de Perigos e Pontos Críticos de Controle (APPCC), por exigência do Ministério da Agricultura, Pecuária e Abastecimento (Mapa). Assim, visa-se garantir a produção de camarão de forma saudável, atendendo às normas de segurança alimentar exigidas pelos mercados nacional e internacional.

$\mathrm{Na}$ fase atual da trajetória tecnológica do cultivo do camarão, percebe-se o surgimento de inovações mais sustentadas, como o cultivo de camarão orgânico; em algumas fazendas da região; o registro, junto ao Instituto Nacional da Propriedade Industrial (INPI), de uma Indicação Geográfica - denominação de origem (Camarão da Costa Negra), conferindo proteção ao camarão produzido no norte do Ceará, pelas suas especificidades, que conferem sabor diferenciado ao camarão. Além disso, algumas fazendas vêm passando por um rigoroso processo de certificação de qualidade ambiental, exigida com a produção de camarão orgânico, que vem se expandido na região.

Verificam-se, ainda, novas oportunidades, como o desenvolvimento e a adoção da tecnologia de sistemas de cultivos de camarões em bioflocos (BFT). Esses sistemas permitem a adequação para as fazendas que praticam o sistema tradicional de produção. Além dessa mudança ocorreu também o desenvolvimento e a adaptação da tecnologia para produzir camarão livre de patógenos (Specific Pathogen Free - SPF); e o desenvolvimento de pesquisas para obter rações de alta qualidade. Essas medidas podem contribuir para o desenvolvimento sustentável da atividade (NATORI et al., 2011).

As inovações no setor têm origem também nas relações dos produtores com universidades e centros de pesquisa regionais e, principalmente, com os fornecedores de ração e as empresas de beneficiamento. Essa contribuição, porém, no caso das universidades, ainda é limitada a poucas atividades associadas ao processo de produção e a um número reduzido de empresas da região. Esses fatos levam às mudanças que estão produzindo inovações contínuas no sistema produtivo do camarão do Nordeste. Algumas inovações observadas, contudo, principalmente nas pequenas e na maioria das médias empresas da região Nordeste, são incrementais de baixa intensidade, referindo-se à incorporação de equipamentos e às melhorias de algumas técnicas de manejo dos cultivos.

\section{Conclusão}

Em decorrência da importância econômica da indústria do cultivo de camarão para a região Nordeste do Brasil, considerado o segmento mais organizado do setor pesqueiro nacional, percebe-se que o seu desenvolvimento dependeu de um complexo arranjo institucional, cuja trajetória tecnológica pode distinguir-se em quatro fases. Incialmente têm-se a introdução e adaptação de tecnologias externas; seguida da intensificação das pesquisas na iniciativa pública e privada; consolidação da atividade, com o uso de uma espécie exótica de crustáceo e domínio da tecnologia de cultivo; e ponto de inflexão no surgimento de inovações. Por outro lado, observa-se o surgimento de uma nova etapa, ou nova trajetória tecnológica no setor, impulsionada pela parceria entre instituições de pesquisa e ensino e associação de produtores.

Nessa nova fase do processo produtivo do camarão, as inovações relevantes no sistema de cultivo de camarão ocorrem ao longo de toda a cadeia produtiva regional. No entanto, a maioria dessas inovações é relacionada a processos e a aquisição de equipamentos, a partir da incorporação de conhecimento com o uso de tecnologias presentes nos bens de capitais. No entanto, também se percebe a adoção de inovações relacionadas com maior atenção dada à sustentabilidade ambiente $\mathrm{e}$ qualidade do produto. 
Apesar disso, percebe-se a introdução de inovações de produto e organizacionais, como sistema de bioflocos, gestão e certificação orgânica e ambiental e, de certa forma, inovações radicais, como o camarão orgânico. Considerando os principais elos da cadeia, esses avanços tecnológicos são percebidos, principalmente, nas grandes e médias empresas de cultivo e nos laboratórios. As pequenas empresas, embora seja maioria, apresentam pouco dinamismo inovativo e operam de forma quase artesanal, utilizando pacote tecnológico de fácil adaptação. Desse modo, cabe aprofundar os estudos para verificar se a nova fase, pela qual o referido setor está passando, é de fato uma nova fase em sua trajetória ou o início de uma nova trajetória tecnológica.

\section{Referências}

ABCC - Associação Brasileira de Criadores de Camarão. O censo da carcinicultura nacional em 2011. Disponível em: $<$ http://www.abcc.com.br>. Acesso em: 2 jul. 2015a.

. Estatísticas ABCC - Balança Comercial de pescado - (2010-2014). Disponível em: <http://www.abcc.com. br>. Acesso em: 2 jul. 2015b.

BARDIN, L. Análise de conteúdo. Lisboa, Portugal: Edições 70, LDA, 2009. 280p.

BORBA, M.; NOGUEIRA, J. Carcinicultura Brasileira: o perfil do setor em cada unidade federativa produtora em 2011. Revista ABCC, v. 15, n. 2, p. 26-29, 2013.

BRASIL. Ministério da Pesca e Aquicultura (MPA). Boletim estatístico da pesca e aquicultura: Brasil 2008-2009. Brasília, 2012.

BRESCHI, S.; MALERBA, F; ORSENIGO, L. Technological regimes and Schumpeterian patterns of innovation. The economic journal, v. 110, n. 463, p. 388-410, 2000.

CARVALHO, J.M.M. et al. A perspectiva para o desenvolvimento da carcinicultura no nordeste brasileiro. Fortaleza: BNB, 2005. (Série Documentos do ETENE, no 2 ).

CARVALHO, S.A.D.; FURTADO, A.T. Estratégias tecnológicas e dinâmica de inovação das empresas agroalimentares no Brasil. Gestão \& Conexões Management and Connections Journal, v. 2, n. 1, p. 47-75, 2013.

CASSIOLATO, J.E.; LASTRES, H.M.M. Sistemas de inovação e desenvolvimento: as implicações de política. São Paulo em Perspectiva, v. 19, n. 1, p. 34-45, 2005.
DODGSON, M.; GANN, D.M.; SALTER, A. The management of technological innovation: strategy and practice. London: Oxford University Press, 2008. 373p.

DOSI, G. Technological paradigms and technological trajectories: a suggested interpretation of the determinants and directions of technical change, Research policy, v. 11, n. 3, p. 147-162, 1982.

. Mudança técnica e transformação industrial: a teoria e uma aplicação à indústria dos semicondutores. Campinas: Editora Unicamp. 2006. 464p.

; MARENGO, L.; PASQUALI, C. How much should society fuel the greed of innovators?: On the relations between appropriability, opportunities and rates of innovation. Research Policy, v. 35, n. 8, p. 11101121, 2006.

DUNHAM, F.B.; BOMTEMPO, J.V.; ALMEIDA, E.L.F. Trajetórias tecnológicas em combustíveis sintéticos: análise dos mecanismos de seleção e indução. Revista Brasileira de Inovação, v. 5, n. 1, p. 99-129, 2006.

FAO. Fisheries and Aquaculture Information and Statistics Service Global Aquiculture Produções - 1950-2013. FAO, 2014. Disponível em: <http://www.fao.org/statis > Acesso em: 18 maio 2015.

FIGUEREIDO, P. Discontinuous innovation capability accumulation in atecomer natural resource-processing firms. Technological Forecasting \& Social Change, n. 77, p. 1090-1108, 2010.

FREEMAN, C. Um pouso forçado a "nova economia"? A tecnologia da informação e o sistema nacional de inovação dos Estados Unidos. In: LASTRES, H.M.M.; CASSIOLATO J.E.; ARROIO, A. (Orgs.). Conhecimento, sistemas de inovação e desenvolvimento. Rio de Janeiro: Ed. UFRJ e Contraponto, 2005. p. 51-81.

FREIRE, A.C.; BALDI, M. Processo inovativo e indicadores estruturais: posição dos atores e trajetória tecnológica na rede de carcinicultura Potiguar. Organizações \& Sociedade, v. 21, n. 69, p. 235-254, 2014.

LOPES F.D.; BALDI, M. Estratégia como contexto interfirma - uma análise a partir da imersão social e da teoria institucional no setor de carcinicultura norte-riograndense. RAM, Revista Administração Mackenzie, v. 14, n. 2, p. 210-242, 2013.

MADRID, R.M. Brasil e o mercado americano de camarões. Panorama da Aquicultura, v. 6, n. 3, 2006.

;) WURMANN, C. O futuro da carcinicultura brasileira. Revista da ABCC, v. 12, n. 2, p. 42-40, 2011.

MALERBA F.; ORSENIGO L. Schumpeterian Patterns of Innovation are Technology-specific. Research Policy, v. 25, n. 3, p. 451-478, 1996. 
NATORI, M.N. et al. Desenvolvimento da carcinicultura marinha no Brasil e no mundo: avanços tecnológicos e desafios. Informações Econômicas, v. 41, p. 61-73, 2011.

OCDE. Manual de Oslo: Proposta de Diretrizes para Coleta e Interpretação de Dados sobre Inovação Tecnológica. Tradução da FINEP. Disponível em: $<$ http://www.finep.gov.br>. Acesso em: 18 maio 2015.

ORMOND, J.G.P. et al. A carcinicultura brasileira. BNDES Setorial, v. 19, p. 91-118, 2004.

ROCHA, I.P. Impactos socioeconômicos e ambientais da carcinicultura brasileira: mitos e verdades. Revista da $A B C C$, v. 7, n. 4, p. 29-36, $2006 a$.

As perdas de oportunidades pelo setor pesqueiro brasileiro, com ênfase para a carcinicultura marinha: histórico, entraves e perspectivas de recuperação. Revista $A B C C$, v. 16, n. 1, p. 19-23, 2006 b.

. A importância da aquicultura e da carcinicultura no contexto da produção mundial de pescado: desafios e oportunidades para o Brasil. Revista $A B C C$, v. 15, n. 2, p. 16-26, 2013.

As perdas de oportunidades pelo setor pesqueiro brasileiro, com ênfase para a carcinicultura marinha: histórico, entraves e perspectivas de recuperação. Revista $A B C C$, v. 16, n. 1, p. 19-23, 2014.

SCOPEL, B.R. Mergulhando na aquicultura asiática: inovações e tecnologias da Ásia para a carcinicultura brasileira. Revista ABCC, v. 16, n. 1, p. 49-51, 2014.

TAHIM, E.F; ARAÚJO, I.F. O processo de aprendizado e de inovação no sistema produtivo da carcinicultura no nordeste brasileiro. Estudos Sociedade e Agricultura, v. 20, n. 1, p. 30-65, 2012. ; . A carcinicultura do nordeste brasileiro e sua inserção em cadeias globais de produção: foco nos APLs do Ceará. Rev. Econ. Sociol. Rural, v. 52, n. 03, p. 567-586, 2014.

;___. Aprendizado, cooperação e capacidade inovativa dos arranjos produtivos locais de cultivo de camarão no estado do Ceará. Revista Brasileira de Gestão e Desenvolvimento Regional, v. 11, n. 2, p. 34-59, 2015.

TIDD, J.; BESSANT, J.; PAVITT, K. Gestão do inovação. 3. ed. Porto Alegre: Bookman, 2008. 420p.

TIGRE, P.B. Gestão da inovação: a economia da tecnologia no Brasil. Rio de Janeiro: Campus. 2006. 282p.

TORRRES, R. Os mistérios do Ceará: a terra onde o litoral come o camarão e a tilápia produzidos em pleno sertão. Seafood Brasil, n. 22, out./dez. 2015.

VIEIRA FILHO, J.E.R. Inovação tecnológica e aprendizado agrícola: uma abordagem schumpeteriana. $154 \mathrm{f}$. Tese (Doutorado em Economia) - Programa de Pósgraduação em Ciências Econômicas, Instituto de Economia, Universidade de Campinas, Campinas, 2009.

WASIELESKY, W.; KRUMMENAUE, D. Cultivo de camarões em sistema de bioflocos: realidades e perspectivas. Revista $A B C C$, v. 15, n. 2, p. 16-26, 2013.

WURMANN G.C.; MADRID, R.M. O desenvolvimento da salmonicultura no Chile: lições de um modelo vigoroso e sua possível aplicação na indústria do cultivo do camarão no Brasil. Panorama da aquicultura, v. 16, n. 93 , p. $14-23,2006$.

Todo o conteúdo deste periódico, exceto onde estiver identificado, está licenciado sob uma Licença Creative Commons (cc by 4.0). 
